\title{
ANALISIS FAKTOR YANG BERPENGARUH PADA BIAYA PELAKSANAAN PERKUATAN BAJA PADA DINDING FURNACE INDUSTRI KACA
}

\section{(Analysis Factors Affecting the Implementation of Steel Strength on Wall Furnace Glass) Industry)}

\author{
Daniel Arie Susanto ${ }^{1)}$, Jane Sekarsari ${ }^{2)}$ \\ ${ }^{1)}$ Magister Teknik Sipil FTSP - Usakti \\ 2) Magister Teknik Sipil FTSP - Usakti \\ Email: danielariesusanto@gmail.com,tamtana.js@gmail.com
}

Diterima: September 2019; Direvisi (Revised): Desember 2019; Disetujui untuk Dipublikasikan (Accepted): Maret 2020

\begin{abstract}
ABSTRAK
Proyek konstruksi perkuatan baja pada dinding furnace cukup berpengaruh dalam menunjang keberhasilan dalam membuat suatu produk. Pada proyek perkuatan baja pada dinding furnace industri kaca perhitungan biaya pelaksanaan yang masih kurang referensi dalam hal perhitungan biaya berkaitan dengan pelaksanaan dibandingkan dengan proyek konstruksi lainnya. Tujuan dari penelitian ini dapat mengidentifikasi faktor yang mempengaruhi biaya pelaksanaan perkuatan baja pada dinding furnace industri kaca. Metode yang digunakan adalah kuesioner, dengan skala pengukuran yang digunakan penelitian ini adalah skala likert. Bentuk pengujian yang digunakan untuk validitas instrumen dilakukan dengan teknik korelasi. Realibilitas instrumen dilakukan dengan menggunakan metode Alpha Cronbahc's dengan membuat faktor skor. Hasil analisis mendapatkan 7 (tujuh) faktor dari 8 (delapan) kategori yang mempengaruhi biaya pelaksanaan perkuatan baja pada dinding furnace industri kaca yaitu Area kerja yang sempit dan bersuhu tinggi, area kerja yang terhalang oleh mesin, perubahan desain pada saat pelaksanaan, terjadinya kemiringan pada saat pemasangan batu tahan api, fluktuasi harga material.
\end{abstract}

Kata kunci: estimasi biaya, pelaksanaan konstruksi, industri kaca

\begin{abstract}
The steel reinforcement construction project on the furnace wall is quite influential in supporting the success in making a product. In steel reinforcement projects in the glass industry wall furnace the calculation of implementation costs is still lacking in reference to the calculation of costs related to the implementation compared to other construction projects. The purpose of this study can identify the factors that influence the cost of implementing steel reinforcement in the glass industry wall furnace. The method used was a questionnaire, with a measurement scale used in this study is a Likert scale. The form of testing used for instrument validity is done by correlation technique. Instrument reliability was performed using the Alpha Cronbah's method by making a score factor. The analysis results get 7 (seven) factors from 8 (eight) categories that affect the cost of implementing steel reinforcement in the glass industry wall furnaces, namely a narrow and high-temperature work area, a work area that is obstructed by machinery, design changes during implementation, and a slope in when installing refractory stones, fluctuations in material prices.
\end{abstract}

Keywords: cost estimation, construction implementation, glass industry 


\section{PENDAHULUAN}

Dalam melaksanakan kegiatan perwujudan konstruksi dan pembangunan masing-masing pihak (sesuai dengan posisinya) saling berinteraksi satu sama lain sesuai dengan hubungan kerja yang telah disiapkan (Sekarsari Jane, 2014). Proyek konstruksi perkuatan baja pada dinding furnace cukup berpengaruh dalam menunjang keberhasilan dalam membuat suatu produk. Berdasarkan area kerjanya konstruksi baja bersuhu tinggi terbagi atas tiga area dengan suhu yang berbeda-beda yaitu : Area Furnace dengan suhu mencapai $75^{\circ} \mathrm{C}$, Area Metal Bath $50^{\circ} \mathrm{C}$, Area LOR \& Lehr $45^{\circ} \mathrm{C}$. Pada proyek perkuatan baja pada dinding furnace industri kaca perhitungan biaya pelaksanaan yang masih kurang referensi dalam hal perhitungan biaya berkaitan dengan resiko-resiko biaya pelaksanaan dibandingkan dengan proyek konstruksi yang lainnya. Penelitian ini bertujuan untuk menganalisi faktor apa saja yang mempengaruhi peningkatan biaya konstruksi perkuatan baja pada dinding furnace industri kaca. Penyebab peningkatan biaya proyek secara umum yaitu ketidaksesuaian antara rencana biaya dengan biaya aktual yang sangat bergantung pada keterampilan, penilaian dan pengalaman dari tim proyek. Sehingga dengan adanya penelitian ini diharapkan bisa menambah referensi dalam hal perhitungan estimasi biaya di area-area khusus pada industri manufaktur, khususnya biaya pelaksanaan proyek konstruksi perkuatan baja pada dinding furnace industri kaca.

\section{STUDI PUSTAKA}

Proyek adalah suatu pekerjaan dengan karakteristik komplek dan melibatkan banyak aktifitas, unik dimana pekerjaan hanya dilaksanakan satu kali, mempunyai waktu pelaksanaan yang tertutup, adanya keterbatasan sumber daya dan biaya, melibatkan banyak disiplin ilmu sehingga sering sekali diperlukan keterlibatan bagian-bagian lain di luar organisasi proyek, goal oriented dan hasil akhir merupakan tujuan utama proyek. Perbedaan proyek dan operasi adalah proyek memiliki batasan dalam pengerjaan ada awal dan ada akhir (kontrak) yang aan menghasilkan sesuatu yang dibutuhkan sedangkan operasi sifatnya lebih mengarah ke kegiatan yang terus berulang untuk melakukan rencana strategis sebagai parameter. Salah satu jenis proyek adalah proyek konstruksi komponen kegiatan utama proyek jenis ini terdiri dari pengkajian kelayakan, desain enjineering, pengadaan dan konstruksi. Menurut (Eshofone et al, 2008), ada beragam kepentingan di industri konstruksi adalah:

a. Klien: klien adalah satu-satunya anggota tim konstruksi yang paling penting. Dia adalah pemrakarsa dan pemodal dari semua proyek, dia mencatat bahwa konstribusi utama yang dapat dibuat klien terhadap keberhasilan operasi industri konstruksi terletak pada keahliannya dalam menentukan kebutuhannya sebelum persiapan desain. Hal ini juga penting bagi klien untuk menetapkan batas biaya proyek pada briefing. Dia juga harus memastikan bahwa ketentuan keuangan yang memadai dibuat sebelum dimulainya proyek apapun.

b. Konsultan: pertimbangan biaya adalah pertimbangan yang paling penting dan mendasar yang harus dihadapi konsultan. Penting untuk melihat bahwa proyek terkandung dalam perkiraan anggaran dan biaya klien. Biaya memiliki kendali akhir atas hampir setiap proyek.

c. Kontraktor: bahwa tugas utama kontraktor adalah mengumpulkan dan mengalokasikan sumber daya tenaga kerja, peralatan dan bahan ke proyek agar tercapai efisiensi maksimum dalam hal waktu, kualitas dan biaya.

Proyek konstruksi pada industri kaca pada penelitian ini pekerjaan patch brick port dinding furnace yang mempunyai tujuan untuk menambal batu sisi samping bagian dalam agar bahan baku yang sudah dibakar di dalam tidak keluar. Lokasi patch brick dinding furnace berada di setiap port regenerator dan tungku utama, port sendiri dipisahkan oleh kolom baja Wide Flange (WF) dengan ukuran 500 x 250 x 30mm dengan jarak kolom ke kolom adalah 6000mm. Dapat dilihat pada Gambar 1. 

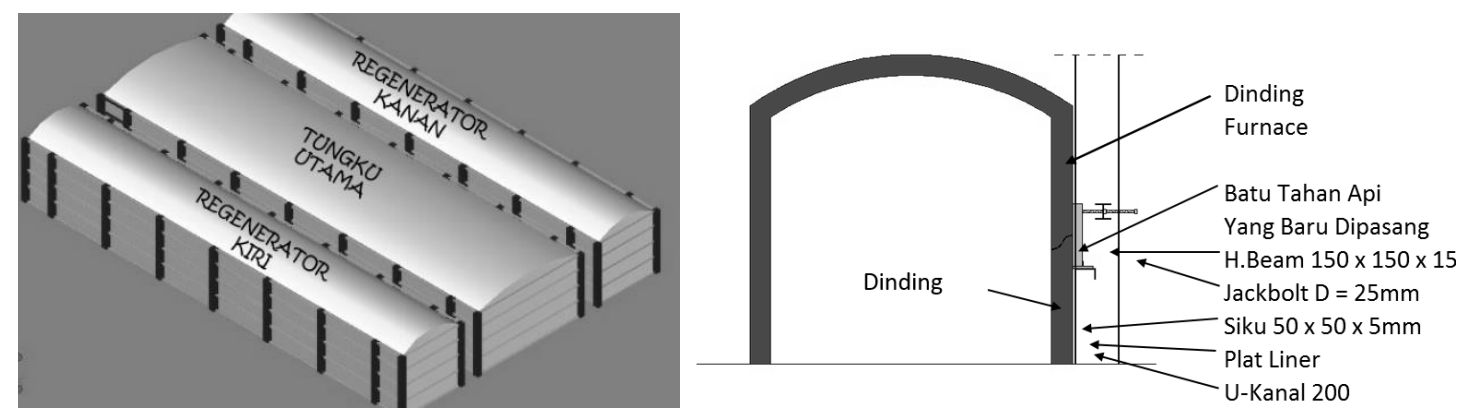

Gambar 1. Tampak 3D dan tampak depan pekerjaan dinding furnace

\section{METODE PENELITIAN}

Penelitian ini dilakukan pada proyek perkuatan baja pada dinding furnace industri kaca, metode yang digunakan untuk meneliti adalah metode kuantitatif, dimana pengumpulan data menggunakan instrumen penelitian, analisis data bersifat kuantitatif/statistik (Sugiyono, 2010). Adapun langkah-langkah dalam proses penelitian dimulai dari mengetahui latar belakang masalah dalam pelaksanaan proyek perkuatan baja pada dinding furnace industri kaca, merumuskan masalah seperti menganalisis faktor dominan dan faktor yang perlu diperhitungkan dalam penyusunan anggaran biaya pelaksananaan perkuatan baja pada dinding furnace industri kaca, menentukan tujuan penelitian yaitu mengidentifikasi faktor yang berpengaruh dan mengetahui faktor yang perlu diperhitungkan, melalui studi pustaka dan penelitian-penelitian terdahulu yang dijadikan referensi dan wawancara pakar dengan pihak yang berkompeten, menentukan faktor yang terkait, penyebaran kuesioner kepada para pihak yang berkompeten, pengumpulan data hasil dari penyebaran kuesioner, uji validitas dan reabilitas, pembuatan faktor skor untuk faktor-faktor yang berpengaruh, kesimpulan dan saran terhadap faktorfaktor tersebut. Secara ringkas penelitian ini dijelaskan pada Gambar 2.

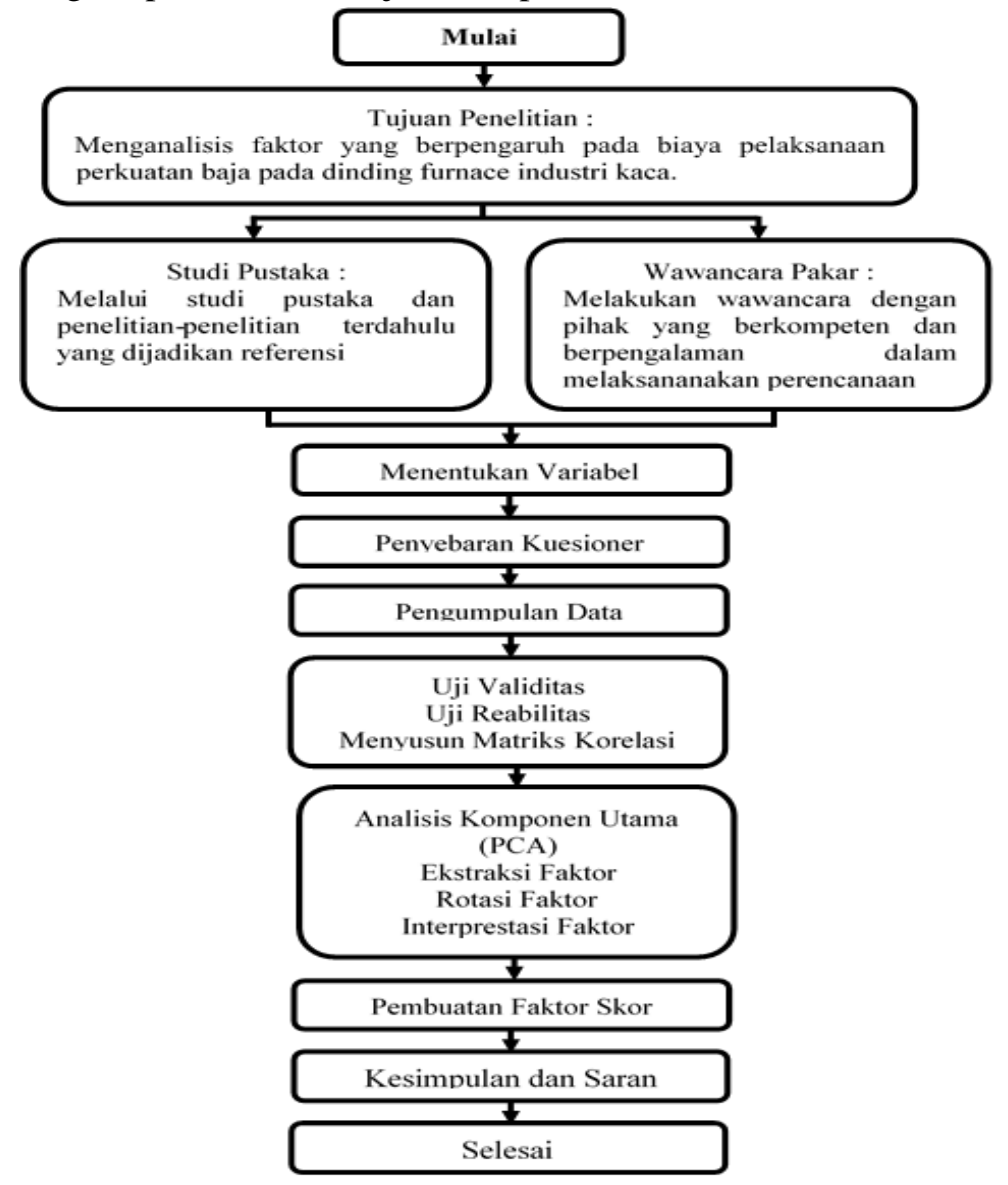

Gambar 2. Bagan alur penelitian

Copyright: J-TESLINK (c) 2020

https://teslink.nusaputra.ac.id 
(Daniel Arie Susanto ${ }^{1)}$, Jane Sekarsari ${ }^{2)}$ ) | J-TESLINK 1 (2);4-6 ISSN 2715-4831 cetak; ISSN 2715-6141 online

Faktor-faktor yang mempengaruhi biaya berdasarkan kajian pustaka dirangkum dalam Tabel 1.

Tabel 1. Identifikasi Faktor-Faktor Hasil Dari Telaah Pustaka Dan Wawancara Pakar

\begin{tabular}{|c|c|c|c|}
\hline No & Kategori & Faktor & $\begin{array}{l}\text { Faktor Yang Mempengaruhi Biaya Pelaksanaan Perkuatan Baja } \\
\text { Pada Dinding Furnace Industri Kaca }\end{array}$ \\
\hline \multirow[t]{3}{*}{1} & Kondisi lokasi & $\mathrm{X} 1$ & Area kerja yang sempit dan bersuhu tinggi \\
\hline & & $\mathrm{X} 2$ & Area kerja yang terhalang oleh mesin \\
\hline & & $\mathrm{X} 3$ & Jarak gudang material dengan gudang alat kerja yang jauh \\
\hline \multirow[t]{3}{*}{2} & Material & $\mathrm{X} 4$ & Kekurangan mataerial umum \\
\hline & & $\mathrm{X} 5$ & Perencanaan pembelian yang buruk dan koordinasi bahan \\
\hline & & X6 & Fluktuasi harga material \\
\hline 3 & Peralatan & $\mathrm{X} 7$ & Menggunakan teknologi baru atau peralatan khusus yang diminta \\
\hline \multirow[t]{2}{*}{4} & Perencanaan & $\mathrm{X} 8$ & Sumber daya yang dibutuhkan \\
\hline & & $\mathrm{X} 9$ & Perencanaan yang salah \\
\hline \multirow[t]{3}{*}{5} & Desain & $\mathrm{X} 10$ & Pemotongan plat liner yang sulit dikarenakan ukurannya kecil \\
\hline & & $\mathrm{X} 11$ & Sulitnya membuat siku support menjadi $65^{\circ}$ agar presisi \\
\hline & & $\mathrm{X} 12$ & Aksesoris support yang dibuat membutuhkan ukuran yang tepat \\
\hline \multirow[t]{10}{*}{6} & $\begin{array}{c}\text { Pelaksanaan } \\
\text { Konstruksi }\end{array}$ & $\mathrm{X} 13$ & Pekerjaan tambahan diluar kontrak \\
\hline & & $\mathrm{X} 14$ & Kurangnya koordinasi pada saat pelaksanaan \\
\hline & & $\mathrm{X} 15$ & Perubahan desain pada saat pelaksanaan \\
\hline & & $\mathrm{X} 16$ & Sulitnya membuka klem cooling duct \\
\hline & & $\mathrm{X} 17$ & Lamanya waktu bongkar baja support sementara \\
\hline & & $\mathrm{X} 18$ & Terjadinya kemiringan pada saat pemasangan batu tahan api \\
\hline & & X19 & Perubahan pada struktur dinding furnace dan regenerator \\
\hline & & $\mathrm{X} 20$ & Kerusakan pada cooling duct pada saat akan dipasang \\
\hline & & $\mathrm{X} 21$ & Tingkat kecelakaan dalam pelaksanaan \\
\hline & & $\mathrm{X} 22$ & Terjadinya penghentian pekerjaan dikarenakan adanya inspeksi \\
\hline \multirow[t]{4}{*}{7} & Manajerial & $\mathrm{X} 23$ & Hubungan antara manajemen dengan tenaga kerja kurang baik \\
\hline & & $\mathrm{X} 24$ & Tingkat persaingan antara tenaga kerja \\
\hline & & $\mathrm{X} 25$ & Kurangnya standar produktivitas \\
\hline & & $\mathrm{X} 26$ & Koordinasi informasi antara pemilik dan pihak kontraktor \\
\hline 8 & Personil & $\mathrm{X} 27$ & Penempatan personil tidak sesuai kompetensi \\
\hline
\end{tabular}

\section{HASIL DAN PEMBAHASAN}

Analisis data ini meliputi 27 faktor yang berpengaruh pada biaya pelaksanaan perkuatan baja pada dinding furnace industri kaca. Kuesioner ini disebar di 2 (dua) daerah yakni DKI Jakarta dan Cikampek (Jawa Barat) terhadap 50 responden yang terlibat langsung dalam pekerjaan pelaksanaan perkuatan baja pada dinding furnace industri kaca akan tetapi kuesioner yang kembali berjumlah 40 responden. Data hasil kompilasi kemudian digunakan sebagai input data ke dalam program SPSS untuk dilakukan analisis lebih lanjut. Uji validitas dan reabilitas dikatakan valild apabila instrumen memiliki nilai korelasi (r) lebih dari $r$ tabel yang disyaratkan. Berdasarkan hasil pengolahan data dapat diketahui bahwa untuk uji validitas data $n=40$ dan derajat kebebasan $=0.05$, maka $r$ tabel $=0.312$ maka semua variabel yang memiliki $r$ hitung $>r$ tabel, dinyatakan valid. Untuk uji reliabilitas didapatkan Cronbach Alpha sebesar 0,740 lebih besar dari 0.6, maka instrumen penelitian ini adalah reliabel. Ekstraksi faktor adalah suatu metode yang digunakan untuk mereduksi data dari beberapa indikator untuk menghasilkan faktor yang lebih sedikit yang mampu menjelaskan korelasi antara indikator yang diobservasi. Hasilnya menunjukan 23 faktor diuji memenuhi persyaratan komunalitas yaitu 
lebih besar dari 0.5 . Untuk indikator (X1) nilai ekstraskinya adalah 0.832 hal ini berarti bahwa $83.2 \%$ varian dari indikator (X1) dapat dijelaskan oleh faktor yang akan terbentuk. Semakin besar nilai ekstraksi menunjukan semakin kuat hubungan dengan faktor yang nantinya akan terbentuk. Dari interprestasi faktor diperoleh informasi bahwa jumlah faktor yang terbentuk adalah 7 faktor yaitu faktor pertama yang mempunyai eigenvalue sebesasr 7.79, faktor kedua yang mempunyai eigenvalue sebesar 4.18, faktor ketiga yang mempunyai eigenvalue sebesar 2.83 , faktor keempat mempunyai eigenvalue sebesar 2.02, faktor kelima mempunyai eigenvalue sebesar 1.64 , faktor keenam mempunyai eigenvalue sebesar 1.39 , faktor ketujuh mempunyai eigenvalue sebesar 1.02. Dari tabel tersebut dapat diperoleh 7 faktor dengan total presentase varians dari 7 faktor tersebut adalah sebesar $33.87 \%+18.17 \%+12.30 \%+8.80 \%+7.12 \%+6.05 \%+4.45 \%$ $=90.75 \%$. Dengan demikian $90.75 \%$ dari seluruh faktor yang ada dapat dijelaskan oleh 7 faktor yang terbentuk dalam hasil interprestasi faktor belum diketahui faktor mana saja kah yang menjadi faktor konstruk. Guna menentukan urutan faktorvar penelitian yang menjadi faktor konstruk dilakukanlah penyusunan faktor skor maka didapatkan faktor yang berpengaruh pada biaya pelaksanaan perkuatan baja pada dinding furnace industri kaca dapat dilihat pada Tabel 2.

Tabel 2. Urutan Faktor Yang Berpengaruh

\begin{tabular}{cclc}
\hline Urutan & Faktor & \multicolumn{1}{c}{ Penyebab } & Skor \\
\hline 1 & X1 & Area kerja yang sempit dan bersuhu tinggi & 0.857 \\
2 & X2 & Area kerja yang terhalang oleh mesin & 0.792 \\
3 & X15 & Perubahan desain pada saat pelaksanaan & 0.758 \\
4 & X18 & Terjadinya kemiringan pada saat pemasangan batu tahan api & 0.754 \\
5 & X6 & Fluktuasi harga material & 0.738 \\
6 & X9 & Perencanaan yang salah & 0.723 \\
7 & X26 & Koordinasi informasi antara pemilik dan pihak kontraktor & 0.689 \\
\hline
\end{tabular}

\section{KESIMPULAN}

Berdasarkan hasil dan analisa pengaruh pada biaya pelaksanaan perkuatan baja pada dinding furnace yang telah dilakukan, maka dapat disimpulkan sebagai berikut:

a) Hasil studi ini menunjukan sebanyak 23 (dua puluh tiga) faktor yang teridentifikasi berdampak langsung terhadap pengaruh pada biaya pelaksanaan pekerjaan perkuatan dinding furnace industri kaca.

b) Dari 23 faktor yang teridentifikasi terdapat 7 (tujuh) faktor yang berpengaruh pada biaya pelaksanaan perkuatan dinding furnace industri kaca yaitu:

1) Area kerja yang sempit dan bersuhu tinggi: Pelaksana lapangan yang juga membuat estimasi kesulitan untuk melihat area pekerjaan yang akan dikerjakan karena suhu yang tinggi.

2) Area kerja yang terhalang oleh mesin: Pelaksana lapangan harus memberikan ide dan keputusan yang cepat dan tepat dalam mengambil tindakan untuk segera dilaksanakan oleh pekerja dan segera melaporkan kepada user ide yang didapatkan untuk menghadapi masalah tersebut.

3) Perubahan desain pada saat pelaksanaan: Masalah ini muncul dari perencanaan dan pengelolaan proyek yang tidak memadai, salah satu masalah termasuk perubahan rencana awal untuk memasang batu tahan api.

4) Terjadinya kemiringan pada saat pemasangan batu tahan api : Pelakasana lapangan dan pekerja memastikan level kemiringan retak batu dinding furnace sejajar dengan pemasangan batu sebelumnya.

5) Fluktuasi harga material: Tren inflasi dan nilai tukar uang yang bisa berubah tiap hari berdampak pada harga material yang terkadang turun naik, sebaiknya pihak kontraktor membuat BQ dengan 
lebih cepat dan tepat begitu pula sebaliknya pihak owner menurunkan SPK dengan catatan sudah disepakati harga final BQ tersebut.

6) Perencanaan yang salah: Tidak mengetahui sumber daya apa yang dibutuhkan pada proyek perkuatan dinding baja furnace, menjadikan menumpuk nya sumber daya yang tidak diperlukan.

7) Koordinasi informasi antara pemilik dan pihak kontraktor: Pihak kontraktor terkadang tidak berkoordinasi tentang informasi apa yang perlu dia dapatkan setiap hari untuk mengetahui perkembangan proyek begitu juga dengan pihak pemilik tidak berkoordinasi mengenai informasi yang terjadi.

\section{DAFTAR PUSTAKA}

Amanto, Daryanto, 1999, Ilmu Bahan, Bumi Aksara, Jakarta.

Asamoah, 2002, Satifsying the Energy Hunger in West Africa a Progress on West Africa Gas Pipeline,

Brooke Patrick Publications, Johannesburg.

Dipohusodo Istimawan, 1996, Manajemen Proyek \& Konstruksi, Kanisius, Jogjakarta.

Enshassi, et al, 2009, Factors Affecting The Performance of Construction Projects in The Gaza Strip, Journal of Civil Engineering and Management. 15 (3). 269-280.

Eshofone, and Patience, F, (2008). "Factors Affecting Cost of Construction In Nigeria." Presented To The Department Of Building University Of Lagos Akoka, Lagos In Partial Fufilment Of The Requirements For The Award Of Masters In Construction Management.

Sekarsari, Jane, 2014, Sistem Informasi Manajemen - Teori dan Konsep Aplikasi Pada Sektor Konstruksi, Universitas Trisakti, Jakarta. 10.58-59,86.

Sugiyono, 2010, Metode Penelitian Kuantitatif Kualitatif dan R\&D, CV, Alfabeta, Bandung.

Paikun, Kadri, T., \& Hudayani Sugara, R. D. (2017). Estimated budget construction housing using linear regression model easy and fast solutions accurate. 2017 International Conference on Computing, Engineering, and Design (ICCED). doi:10.1109/ced.2017.8308095.

Paikun; Muhammad Kahpi; Rina Krisnawati; Andri Agustian; Randi Rohimat; Jasmansyah. 2019. Estimates of Material Need on Houses Construction Using Regression Model Program. Published In: 2018 International Conference on Computing, Engineering, and Design (ICCED). Date Added to IEEE Xplore: 15 April 2019. DOI: 10.1109/ICCED.2018.00027.

Paikun. 2019. Conceptual Estimation Program Construction Costs and Material Needs. International Journal Engineering and Applied Technology (IJEAT) 2 (1), 11-26 Vol. 2, 2019. 